\title{
Surviving the winter: Tetramorium sibiricum n. sp., a new Central Siberian ant species (Hymenoptera: Formicidae)
}

\author{
Bernhard SEIFERT ${ }^{1}$ if \\ SeIFERT, B. (2021). Surviving the winter: Tetramorium sibiricum n. sp., a new Central Siberian ant species (Hymenoptera: Formicidae). \\ Osmia, 9: 15-24. https://doi.org/10.47446/OSMIA9.3
}

\begin{abstract}
A new species of the thermophilous Tetramorium caespitum species complex, T. sibiricum n. sp., is described from the Central Siberian region near Ulan Ude that has mean January temperatures of $-24^{\circ} \mathrm{C}$. The new species is clearly separable from the related species, T. indocile SANTSCHI, 1927 and T. caespitum (LINNAEUS, 1758), by exploratory data analyses of 35 phenotypic characters and by a discriminant analysis of seven phenotypic characters. A key to these three species, which all might occur in Central Siberia, is provided. The zoogeographic divide called the REINIG Line (DE LATTIN, 1967) is considered to be important in separating the ranges of Central and East Palaearctic ant species with less strong cold-hardiness. Based on images of type specimens, Tetramorium annectens PISARSKI, 1969 is recognized as heterospecific from T. tsushimae EMERY, 1925.
\end{abstract}

Keywords $\mid$ cryptic species $•$ cold-hardiness $•$ zoogeographic divide $\bullet$ numeric morphology-based alpha-taxonomy $\cdot$ Tetramorium caespitum species complex

Survivre en hiver : Tetramorium sibiricum n. sp., une nouvelle espèce de fourmi centro-sibérienne (Hymenoptera: Formicidae)

\begin{abstract}
Résumé
Une nouvelle espèce de fourmi appartenant au complexe d'espèces thermophiles Tetramorium caespitum, T. sibiricum n. sp., est décrite de Sibérie centrale, dans la région proche de Ulan Ude qui présente des températures moyennes en janvier de $-24^{\circ} \mathrm{C}$. Cette espèce est clairement différentiable des espèces apparentées, T. indocile SANTSCHI, 1927 et T. caespitum (LINNAEUS, 1758), par l'analyse exploratoire de données de 35 caractères phénotypiques et par l'analyse discriminante de sept caractères phénotypiques. Une clef dichotomique pour identifier ces trois espèces, qui peuvent être toutes trois présentes en Sibérie Centrale, est proposée. Une division zoogéographique appelée la Ligne de REINIG (DE LATTIN, 1967) est considérée comme importante pour séparer les aires de répartition des espèces de fourmis moins résistantes au froid des zones Centrale et Est Paléarctique. À travers l'analyse d'images de spécimens types, Tetramorium annectens PISARSKI, 1969 est reconnue comme étant hétérospécifique à T. tsushimae EMERY, 1925.
\end{abstract}

Mots-clefs | espèces cryptiques $\cdot$ résistance au froid $•$ division zoogéographique $\cdot$ taxonomie alpha par analyse morphologique numérique $\cdot$ groupe d'espèces Tetramorium caespitum

Reçu • Received | 02 March 2021 || Accepté • Accepted |26 April 2021 || Publié (en ligne) • Published (online) | 29 April 2021 Reviewers | M. FoX • H. WAGNER || http://zoobank.org/D029128F-2296-4AF4-A7F2-4BC9392202F6

\section{INTRODUCTION}

In 2019, the author received eleven nest samples of Tetramorium workers collected by Igor ANTONOV in two sites in the surroundings of Irkutsk and two sites in stony steppe habitats southwest of Ulan Ude. With mean January temperatures of $-21^{\circ} \mathrm{C}$ (Irkutsk) and $-24^{\circ} \mathrm{C}$ (Ulan Ude), these Central Siberian sites represent the most winter-cold places worldwide from which Tetramorium ants are known so far. All collected ants belonged to the Tetramorium caespitum complex - an ant group in which some species appear almost inseparable based upon worker morphology.
Subjective visual inspection of the samples surprisingly suggested that the ants from near Ulan Ude should represent another species than those from Irkutsk.

The recent revision of the Westpalaearctic members of the Tetramorium caespitum complex published by WAGNER et al. (2017) strongly improved the taxonomic knowledge on this difficult ant group and distinguished ten species: Tetramorium caespitum (LINNAEUS, 1758), T. impurum (FOERSTER, 1850), T. indocile SANTSCHI, 1927, T. immigrans 
SANTSCHI, 1927, T. hungaricum RÖSZLER, 1935, T. staerckei KRATOCHVIL, 1944, T. fusciclava CONSANI \& ZANGHERI, 1952, T. alpestre STEINER et al. 2010, T. breviscapus WAGNER et al., 2017 and T. caucasicum WAGNER et al., 2017. Based on the known climate niche, only two of these species would be capable of postglacial invasion of the Baikal region. This is firstly $T$. caespitum, as the only species of the group known from Fennoscandia and found there north to $63^{\circ} \mathrm{N}$ (SEIFERT, 2018) and secondly $T$. indocile which is known from near Chelyabinsk in Western Siberia and the montane zone of the Tian Shan (WAGNER et al., 2017). Using exploratory data analyses of a very complex morphological character system, this paper provides evidence for the existence of an undescribed Central Siberian species Tetramorium sibiricum n.sp. and of two further species occurring in Siberia west of the zoogeographic divide known as the REINIG Line (DE LATTIN, 1967).

\section{MATERIAL AND METHODS}

A total of 111 nest samples with 359 worker individuals were investigated. These were 7 samples with 21 workers of Tetramorium sibiricum n. sp., 20 samples with 72 workers of $T$. indocile and 84 samples with 266 workers of T. caespitum. The material originated from the whole known Palaearctic range of these species with exception of unclear samples near to T. caespitum from Iberia. As a rule, worker ants were taken directly from the nest populations - hence representing nest samples of close kinship. Detailed data on geographic origin and morphology of these samples are

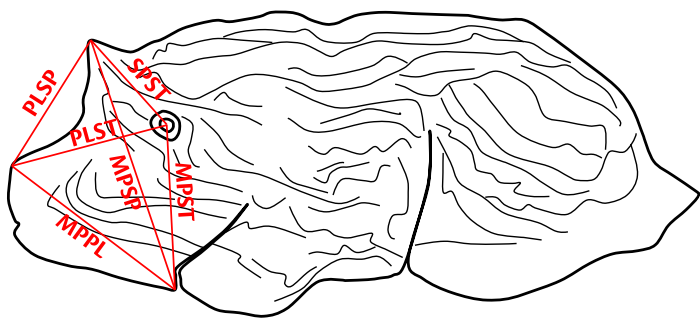

Figure 1. Measuring lines on propodeum and metapleuron (after WAGNER et al., 2017, modified). given in the digital supplementary information SI1 and SI2. Equipment and methodology of stereomicroscopic evaluation is described elsewhere (e.g. SEIFERT, 2020). Numeric description was performed in a total of 35 characters which are more thoroughly described in STEINER et al. (2010) and WAGNER et al. (2017). I repeat here the character descriptions with the wording of some characters partially changed (box $A+$ figures 1-3).

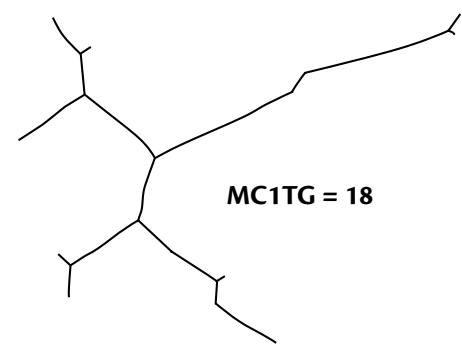

Figure 2. Example of evaluating microsculpture elements on frontal dorsum of 1st gaster tergite (after WAGNER et al., 2017)

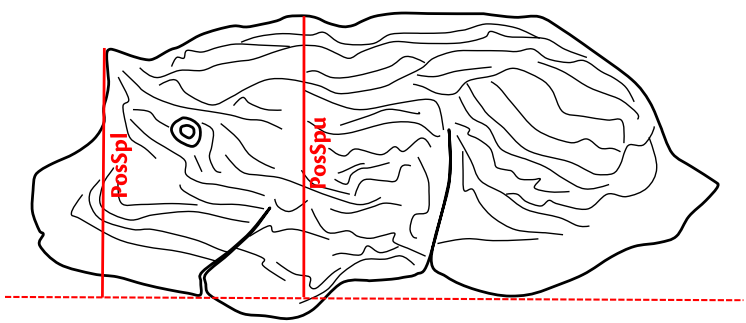

Figure 3. Measuring height of spine tips and of mesosoma (after WAGNER et al., 2017, modified).

Box A. Phenotypic characters used in this study (after STEINER et al., 2010 and WAGNER et al., 2017, partially changed).

\begin{abstract}
- ALPH. Angle between the imaginary line from spine tip to center of propodeal stigma and the imaginary line from spine tip to caudodorsal corner of the propodeal lobe (figure 1); calculated as $\cos \alpha=\left(\mathrm{SPST}^{2}+\mathrm{PLSP}^{2}-\mathrm{PLST}^{2}\right) /\left(2^{*}\right.$ SPST $\left.^{*} \mathrm{PLSP}\right)$.

- BETA. Angle between the imaginary line from anterioventral corner of the metapleuron to center of propodeal stigma and the imaginary line from anterioventral corner of the metapleuron to the caudodorsal corner of propodeal lobe; calculated as $\cos \beta=\left(\mathrm{MPST}^{2}+\mathrm{MPPL}^{2}-\mathrm{PLST}^{2}\right) /\left(2^{*} \mathrm{MPST} T^{*} \mathrm{MPPL}\right)$.

- CL. Maximum cephalic length in median line; the head must be carefully tilted to the position with the true maximum; excavations of occiput and/or clypeus reduce CL. Surface irregularities due to sculpture, carinae in particular, are considered by averaging between peaks and valleys of sculpture.
\end{abstract}

- CS. cephalic size; the arithmetic mean of CL and CW, used as a less variable indicator of body size.

- CW. maximum cephalic width across eyes.

- dCV. Mean distance of longitudinal carinae /carinulae of sculpture on central vertex in dorsal view. The transversal counting line is placed at level of anterior eye margin and is demarcated by the imagined prolongations of posterior parts of the frontal carinae; the distance between the frontal carinae is divided by the number of longitudinal sculpture elements crossing it; sculpture elements just touching the measuring line and those exactly at its endpoints are counted as 0.5. - DELT. Angle between the imaginary line from caudodorsal corner of propodeal lobe to spine tip and the imaginary line from caudodordal corner of propodeal lobe to anterioventral corner of metapleuron; calculated as $\cos \delta=\left(\mathrm{PLSP}^{2}+\mathrm{MPPL}^{2}-\mathrm{MPSP}^{2}\right) /\left(2^{*} \mathrm{PLSP} \mathrm{P}^{*} \mathrm{MPPL}\right)$. 
- EL. Maximum large diameter of the elliptic eye. All structurally defined ommatidiae, pigmented or not, are included.

- EPSI. Angle between the imaginary line from the center of the propodeal stigma to the caudodorsal corner of the propodeal lobe and the imaginary line from the center of the propodeal stigma to the anterioventral corner of the ventral margin of the metapleuron; calculated as $\cos \varepsilon=\left(\mathrm{PLST}^{2}+\mathrm{MPST}^{2}-\mathrm{MPPL}^{2}\right) /\left(2^{*} \mathrm{PLST}{ }^{*} \mathrm{MPST}\right)$.

- EW. Maximum small diameter of the elliptic eye. All structurally defined ommatidiae, pigmented or not, are included.

- FL. Maximum anterior distance of frontal carinae; when FL is not defined because frontal carinae converge frontad anterior of the FRS level, $\mathrm{FL}$ is taken equal to FRS

- FRS. Distance of the frontal carinae immediately caudal of the posterior intersection points between frontal carinae and the lamellae dorsal of the torulus. If these dorsal lamellae do not laterally surpass the frontal carinae, the deepest point of scape corner pits may be taken as reference line. These pits take up the inner corner of scape base when the scape is fully switched caudad and produce a dark triangular shadow in the lateral frontal lobes immediately posterior of the dorsal lamellae of scape joint capsule. Only measured, if FL is not defined.

- GAMM. Angle between the imaginary line from the center of the propodeal stigma to the tip of the spine and the imaginary line from the center of the propodeal stigma to the caudodorsal corner of the propodeal lobe; calculated as $\cos \gamma=$ $\left(S P S T^{2}+\right.$ PLST $^{2}-$ PLSP $\left.^{2}\right) /\left(2^{*} S P S T^{*} P L S T\right)$.

- ML. Mesosoma length measured in dorsal view from the caudalmost portion of propodeum to the anteriormost margin of the pronotal slope (i. e. the breaking point where the coarser sculpture of the pronotal slope changes into the finer sculpture of anterior pronotal shield); equivalent measuring also possible in lateral view.

- MPPL. Distance between anterioventral corner of the ventrolateral margin of the metapleuron and caudodorsal corner of propodeal lobe (figure 1). When there is no corner, measure to the most distant point of caudodorsal propodeal lobe. This does not necessarily mean a coincidence of this point with PL but the effective error in measuring

- MPSP. Maximum distance between the anterioventral corner of the metapleuron and the tip of the spine (figure 1).

- MC1TG. Quantification of stickman-like or reticulate microsculpture units on anterior surface of 1st gastral tergite (use > $150 \times$ magnification): number of connected lines building units and being separated by line intersections and by angular direction changes $>10^{\circ}$ is counted. Also very short lines are full counts. Arithmetic means of at least three units per worker are taken. In example of figure 2, MC1TG is 18.

- MPST. Maximum distance from the anterioventral corner of the ventrolateral margin of the metapleuron to the center of the propodeal stigma (figure 1).

- MW. Maximum mesosoma width.

- PeH. Maximum petiole height; the more or less straight section of ventral petiolar profile at node level is the reference line perpendicular to which the maximum height of petiole node is measured at node level. Note that maximum PEH is not necessarily found at the level of node top; it is the longest section line achieved during shifting of the petiole from frontal to caudal.

- PeNL. Maximum length of petiolar node from the dorsocaudal corner of petiole to anterior petiolar slope; the measuring line is directed orthogonal to a reference line formed by the dorsalmost linear part of anterior petiolar slope.

- PeW. Maximum width of petiole.

- PLSP. Distance between the summit of the caudodorsal corner of the propodeal lobe to the tip of the spine (figure 1). MPPL is low.

- PLST. Distance between the summit of the caudodorsal corner of the propodeal lobe and the center of the propodeal spine (figure 1). - PoOc. Postocular distance; using the cross-scaled ocular micrometer the head is adjusted to the measuring position of $\mathrm{CL}$ caudal measuring point: median occipital margin as average between peaks and valleys of microsculpture; frontal measuring point: median head at the level of the posterior eye margin; because of head asymmetries, the average of left and right postocular distance is calculated.

- PosSPI. Orthogonal distance of the uppermost point of spine tip to a ventral reference line of the mesosoma. The ventral reference line is the line from the ventralmost point of the pronotum to the ventralmost point of the metapleuron (figure 3). With the graduated scale of the ocular micrometer directed perpendicular in the visual field, this reference line is brought to coincidence with the horizontal line of the cross-scale at magnifications of about $\times 100$. Then, at magnifications of $\geq \times 250$, the mesosoma is carefully tilted to a position in which the ventralmost point of the metapleuron and the tip of the spine are at the same focal level. Note that this character is not necessarily measured in lateral view, but frequently in a dorsolateral view.

- PosSPu. Measured in the same adjustment as for PosSPI and orthogonal to the ventral reference line. The distance of the uppermost point of spine tip to the dorsalmost point of propodeum. Note that this point is in the given adjustment usually behind the median line of propodeum and can only be found after focussing movements. With the graduated scale of the ocular micrometer kept perpendicular in the visual field, focussing cannot induce a parallax error.

- POTCos. Number of post-oculo temporal costae and costulae as mean of both head sides. With head in lateral view and the longitudinal axis of head adjusted horizontally, counted by focussing along a perpendicular line from the caudalmost point of eye down to underside of head. Costae/ costulae just touching the measuring line are counted as 0.5 , those positioned just at ventral margin of head silhouette are not counted. A costa beginning exactly at the upper reference point is counted 0.5 .

- PpH. Maximum height of postpetiole measured perpendicular to the suture between dorsal and ventral sclerites. Note that maximum $\mathrm{PpH}$ is not necessarily found at the level of node top; it is the longest section line achieved during shifting of the petiole from frontal to caudal.

- PpW. Maximum width of postpetiole

- PreOc. Preocular distance in lateral view; measured as the shortest distance between the anterior eye margin and the sharp frontal margin of the gena. Do not confuse this margin with the edge of the basal mandibular wulst.

- PnHL. Length of the longest hair near to the corner of antolateral pronotum; arithmetic mean of both sides.

- SLd. Maximum straight line scape length in dorsal view from the most proximal point of basal scape lobe to most distal point of scape end.

- SPBA. Smallest distance of the outer margins of the spines at their base, measured in dorsofrontal view. If the lateral margins of spines diverge continuously from the tip to the base, a smallest distance at base is not defined. In this case, SPBA is measured at the level of the bottom of the interspinal meniscus.

- SPST. Distance between the tip of the spine and the center of the propodeal stigma (figure 1).

- SPWI. Maximum distance between outer margins of spines; measured in same position as SPBA.

- SWd. Maximum scape width which is given in the distal third of scape; transmitted light is used to measure the real cuticular surface and not the pubescence surface.

These primary data were transformed into the thirty shape variables $\mathrm{CL} / \mathrm{CW}$, FL/CS, PoOc/CL, SLd/CS, SWd/CS, EL/CS, EW/CS, PreOc/CS, ML/CS, PosSPL/CS, PosSPu/CS, MPSP/CS, MPST/CS, SPST/CS, PLST/CS, MPPL/CS, PLSP/CS, MW/CS, PeW/CS, PpW/CS, SPBA/CS, SPWI/CS, PeH/CS, PeNL/CS, $\mathrm{PpH} / \mathrm{CS}, \mathrm{ALPH}, \mathrm{BETA}, \mathrm{GAMM}, \mathrm{DELT}$ and EPSI. This gives together with the three sculpture variables $\mathrm{dCV}$, POTCos and MC1TG, the setae variable PnHL/CS and the indicator of absolute body size CS a total of 35 considered characters.

In order to show in comparative tables interspecific differences independent of body size and to increase 
resolution of principle component analyses, a removal of allometric variance (RAV) was performed for worker ants following the basic procedure described by SEIFERT (2008). Evaluation of scatter plots suggested the use of linear monophasic allometry functions. RAV was calculated assuming all individuals to have a cephalic size of $\mathrm{CS}=0.75 \mathrm{~mm}$. RAV functions were calculated as the arithmetic mean of the species-specific functions of eight Palaearctic species with more than 50 workers measured per species - i. e. Tetramorium alpestre, T. caespitum, T. fusciclava, T. hungaricum, T. impurum, T. immigrans, $T$. indocile and T. staerckei (for primary data see supplementary information SI2). The RAV functions are given in the box $B$.

Using these 34 RAV-corrected characters and cephalic size CS as input, three different forms of exploratory data analyses (EDA) using nest centroids as input data were run (NC clustering, SEIFERT et al., 2013). These were hierarchical NC-Ward clustering, the hierarchical method NC-part.hclust and the iterative vector-quantization method NCpart.kmeans - the latter two methods are implemented in partitioning algorithms based on recursive thresholding (for details see CSÖSZ \& FISHER 2015). A controlling linear discriminant analysis (LDA) was run with species hypotheses being formed for samples in which the EDA's arrived at identical classifications whereas samples with controversial classification were run as wild-cards. The final classification ("final species hypothesis") was established by the LDA in an iterative procedure and there remained no undecided cases even if their posterior probabilities were close to 0.5 . Principal component analysis (PCA), LDA, and ANOVA tests were run with the SPSS 15.0 software package.
Box B. RAV functions used in this work.

\begin{tabular}{|c|c|c|}
\hline $\mathrm{CL} / \mathrm{CW}_{750}$ & $=$ & $\mathrm{CL} / \mathrm{CW} /\left(-0.0955^{*} \mathrm{CS}+1.0853\right)^{*} 1.0137$ \\
\hline SLd / CS 750 & $=$ & SLd / CS / (+ 0.0379*CS + 0.7493)*0.7778 \\
\hline SWd / CS 750 & $=$ & SWd / CS / $\left(-0.00852^{*} \mathrm{CS}+0.10252\right)^{*} 0.09613$ \\
\hline PoOc / CL750 & $=$ & PoOc / CL / (- 0.0547*CS + 0.4299)*0.3889 \\
\hline PreOc / CS 750 & $=$ & PreOc /CS / $\left(+0.01644^{*} \mathrm{CS}+0.2346\right)^{*} 0.2469$ \\
\hline $\mathrm{FL} / \mathrm{CS}_{750}$ & $=$ & $\mathrm{FL} / \mathrm{CS} /\left(+0.0216^{*} \mathrm{CS}+0.3723\right)^{*} 0.3885$ \\
\hline$d_{C} V_{750}$ & $=$ & $\mathrm{dCV} /\left(+13.96^{*} \mathrm{CS}+11.89\right)^{*} 22.37$ \\
\hline $\mathrm{EL} / \mathrm{CS}_{750}$ & $=$ & EL / CS / $\left(-0.0016^{*} C S+0.2038\right)^{*} 0.2026$ \\
\hline $\mathrm{EW} / \mathrm{CS}_{750}$ & $=$ & $\mathrm{EW} / \mathrm{CS} /\left(+0.0011^{*} \mathrm{CS}+0.1522\right)^{*} 0.1531$ \\
\hline $\mathrm{PnHL} / \mathrm{CS}_{750}$ & $=$ & Pnhl / CS / $(-0.0148 * C S+0.2662)^{*} 0.2551$ \\
\hline $\mathrm{MW} / \mathrm{CS}_{750}$ & $=$ & $\mathrm{MW} / \mathrm{CS} /\left(+0.1124^{*} \mathrm{CS}+0.5555\right)^{*} 0.6398$ \\
\hline$M L / C_{750}$ & $=$ & $\mathrm{ML} / \mathrm{CS} /\left(+0.2610^{*} \mathrm{CS}+0.9824\right)^{*} 1.1781$ \\
\hline SPBA / CS & $=$ & SPBA / CS / $\left(+0.1353^{*} \mathrm{CS}+0.1620\right)^{*} 0.2635$ \\
\hline SPWI / CS & $=$ & SPWI / CS / $\left(+0.1958^{*} \mathrm{CS}+0.1315\right)^{*} 0.2784$ \\
\hline Pew / CS 750 & $=$ & Pew / CS / $\left(+0.0734^{*} \mathrm{CS}+0.2620\right)^{*} 0.3171$ \\
\hline PpW / CS750 & $=$ & $\mathrm{PpW} / \mathrm{CS} /\left(+0.0600^{*} \mathrm{CS}+0.3588\right)^{*} 0.4038$ \\
\hline PosSPI / CS 750 & $=$ & PosSPI / CS / $\left(+0.1111^{*} \mathrm{CS}+0.3362\right)^{*} 0.4195$ \\
\hline PosSPu / CS 750 & $=$ & PosSPu / CS / $\left(-0.0519^{*} \mathrm{CS}+0.1104\right)^{*} 0.0715$ \\
\hline MPSP / CS 750 & $=$ & MPSP / CS / $\left(+0.1255^{*} C S+0.3451\right)^{*} 0.4392$ \\
\hline MPST / CS 750 & $=$ & MPST / CS / $\left(+0.0536^{*} \mathrm{CS}+0.2266\right)^{*} 0.2668$ \\
\hline SPST / CS 750 & $=$ & SPST / CS / $\left(+0.0793^{*} \mathrm{CS}+0.1418\right)^{*} 0.2013$ \\
\hline PLST / CS 550 & $=$ & PLST / CS / $+0.0253^{*} \mathrm{CS}+0.24$ \\
\hline MPPL / CS 750 & $=$ & MPPL / CS / $\left(+0.0359^{*} \mathrm{CS}+0.3257\right)^{*} 0.3526$ \\
\hline PLSP / CS 750 & $=$ & PLSP / CS / $\left(+0.0584^{*} \mathrm{CS}+0.1823\right)^{*} 0.2261$ \\
\hline $\mathrm{PeH} / \mathrm{CS}_{750}$ & $=$ & $\mathrm{PeH} / \mathrm{CS} /(0 . \mathrm{C}$ \\
\hline $\mathrm{PpH} / \mathrm{CS}_{750}$ & $=$ & $\mathrm{PpH} / \mathrm{CS} / \mathrm{C}$ \\
\hline PeNL / CS750 & $=$ & $\left..0282^{*} \mathrm{CS}+0.2723\right)^{*} 0.2512$ \\
\hline $\mathrm{ALPH}_{750}$ & - & $\mathrm{ALPH} /\left(-19.87^{*} \mathrm{CS}+90.63\right)^{*} 75.73$ \\
\hline $\mathrm{BETA}_{750}$ & $=$ & BETA $/\left(-0.66^{*} \mathrm{CS}+48.10\right)^{*} 47.61$ \\
\hline $\mathrm{GAMM}_{750}$ & $=$ & GAMM / $(+6.10 * C S+51.82) * 56.39$ \\
\hline DELT750 & - & DELT / (+ 19.01*CS + 82.01)*96.26 \\
\hline EDG & $=$ & EPSI / $\left(-4.01^{*} \mathrm{CS}+88.12\right)^{*} 85.11$ \\
\hline & $=$ & POTCOS / $\left(21.76^{*} \mathrm{CS}-6.74\right)^{*} 9.58$ \\
\hline MC1TG 750 & $=$ & MC1TG / $\left(1.20^{*} \mathrm{CS}+13.58\right)^{*} 14.5$ \\
\hline
\end{tabular}

\section{RESULTS AND DISCUSSION}

NC-Ward and NC-part.hclust arrived at identical classifications suggesting the existence of three species (figure 4) with the latter EDA exposing $5.4 \%$ of the 111 samples as unclassified outliers. The controlling LDA was run with stepwise character reduction and confirmed $98.2 \%$ of the classifications. The three species are identified here as $T$. indocile, T. sibiricum n. sp. and T. caespitum. The reduction from 35 to 21 characters in a stepwise LDA solved the problem of character overfitting in T. indocile with 72 workers being investigated but not in T. sibiricum n. sp. where data for only 21 workers in seven samples were available (figure 5). In order to provide additional evidence for the justification of T. sibiricum n. sp. cluster, a PCA was run considering the selected 21 characters $\mathrm{CS}, \mathrm{CL} / \mathrm{CW}_{750}$, $\mathrm{SLd} / \mathrm{CS}_{750}, \mathrm{SWd} / \mathrm{CS}_{750}, \mathrm{PoOC} / \mathrm{CL}_{750}, \mathrm{FL} / \mathrm{CS}_{750}, \mathrm{dCV}_{750}, \mathrm{EL} / \mathrm{CS}_{750}$, $\mathrm{EW} / \mathrm{CS}_{750}, \mathrm{PnHL} / \mathrm{CS}_{750}, \mathrm{MW} / \mathrm{CS}_{750}, \mathrm{ML} / \mathrm{CS}_{750}, \mathrm{SPBA} / \mathrm{CS}_{750}$, $\mathrm{SPWI} / \mathrm{CS}_{750}, \mathrm{Pew} / \mathrm{CS}_{750}, \mathrm{PosSPu} / \mathrm{CS}_{750}, \mathrm{SPST} / \mathrm{CS}_{750}, \mathrm{DELT}_{750}$, EPSI $_{750}$, POTCOS $_{750}$ and MC1TG 750 .

Only the first seven components extracted by this PCA were then used as input in a LDA which solved the overfitting problem in T. sibiricum n. sp. that was confirmed as a clearly separate cluster with posterior probabilities of $p>0.998$ for each sample (figure 6). As a result, all three exploratory data analyses fully agreed in classifications of T. sibiricum n.sp. whereas the few disagreements (a mean of $1.8 \%$ of the total) occurred in the T. indocile and T. caespitum samples.
These data show that three species of the T. caespitum complex occur in Siberia west and north of the Reinig Line. This faunal divide separates East Siberian, Inner Mongolian, Chinese and Tibetan species from those of Central Siberia, West Siberia and the Turanian region (DE LATTIN, 1967). In ants, the REINIG Line is crossed only by very cold resistant species as for example Lepthothorax acervorum (FABRICIUS, 1793), Camponotus herculeanus (LINNAEUS, 1758), Lasius flavus (FABRICIUS, 1782), Formica picea NYLANDER, 1846, Formica gagatoides RUZSKY, 1904, Formica lugubris ZETTERSTEDT, 1838, Formica exsecta NYLANDER, 1846, Formica manchu WHEELER, 1929, Formica pisarskii DLUSSKY, 1964 or Formica uralensis RUZSKY, 1895 (DLUSSKY, 1967; FRANCOEUR, 1983; SEIFERT, 2000, 2021). Considering the lesser coldhardiness of Tetramorium ants, it appears most unlikely that species described from China or Japan could have invaded Central and West Siberia. Postglacial immigration should have occurred here from the southwest. This considerably reduces the spectrum of possible senior synonymies to be considered in case of Tetramorium sibiricum n. sp. (see below).

A detailed consideration of the characters one by one (table I) shows that Tetramorium sibiricum n.sp. differs from T. indocile in having a longer scape, a more developed sculpture on postocular head sides, a narrower petiole and postpetiole, longer pronotal setae and a longer mesosoma 

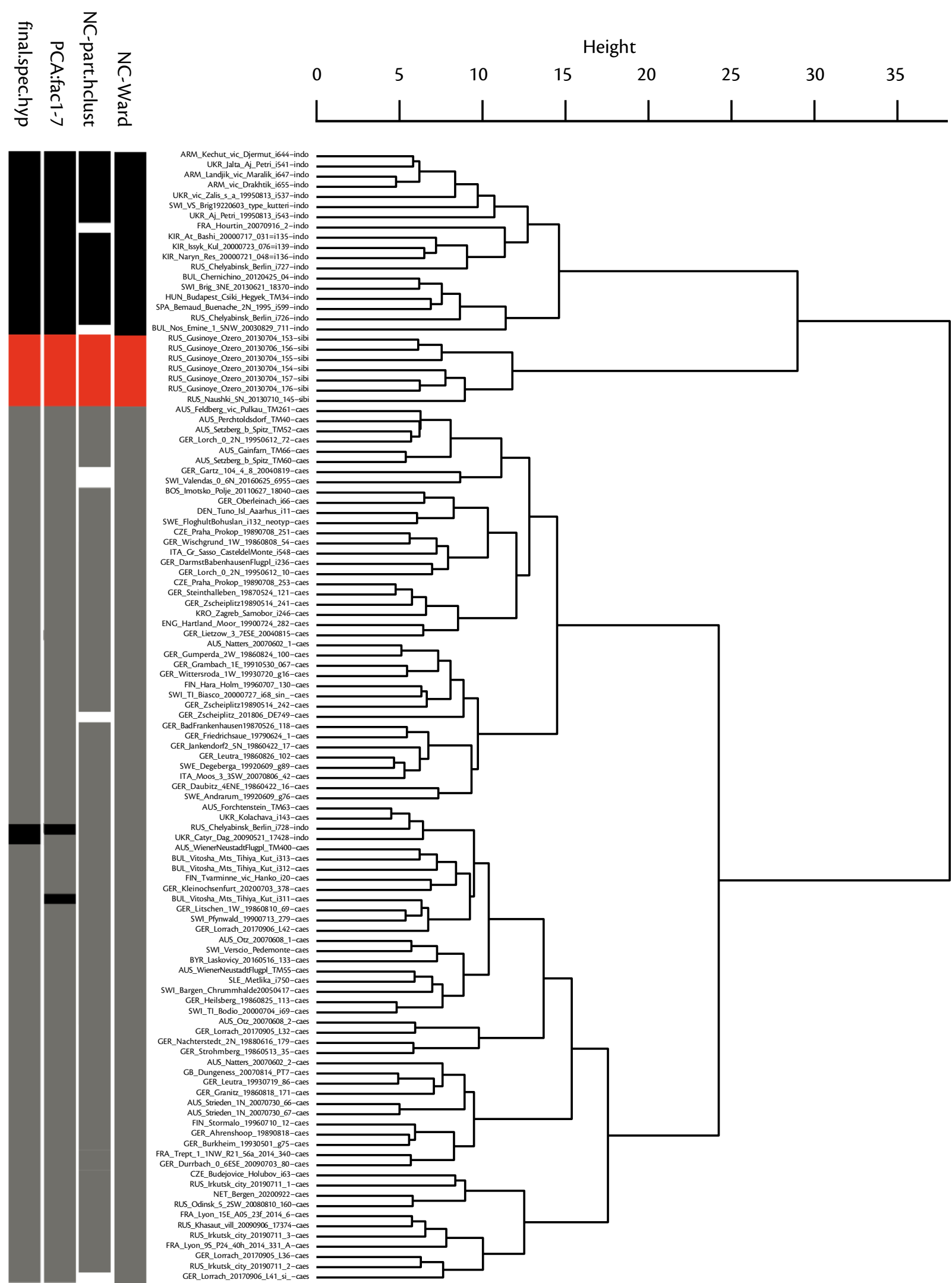

Figure 4. Classification of nest samples of Tetramorium indocile (black bars, $n=20$ ), T. sibiricum n. sp. (red bars, $n=7$ ) and T. caespitum (grey bars, $n=84$ ) by NC-Ward, NC-part.hclust clustering and a principal component analysis. White bars indicate outliers in NC-part.clust. The classification error in each of three exploratory data analyses relative to the controlling linear discriminant analysis is $1.8 \%$. Twenty-one phenotypic characters were considered.

and eye. The main differences to $T$. caespitum are the narrower petiole and postpetiole, the more developed sculpture and microsculpture on postocular head sides and on dorsum of $1^{\text {st }}$ gaster tergite, the higher postpetiole, the longer scape and eye and a longer distance from spine tip to dorsocaudal corner of metapleural lobe. 
Table I. Arithmetic mean and standard deviation of morphometric data of the three Siberian Tetramorium species. Removal of allometric variance in the 34 shape, sculpture and seta characters has been performed for the condition of all individuals having a cephalic size of CS $=750 \mu \mathrm{m}$. The columns with $\mathrm{F}$ and $p$-values of a univariate ANOVA are placed between the columns of the species compared. The most separating characters are indicated by $F$ values in red heavy type.

\begin{tabular}{|c|c|c|c|c|c|c|c|}
\hline & $\begin{array}{c}\text { caespitum } \\
(n=266)\end{array}$ & $\begin{array}{c}\text { ANOVA } \\
\mathrm{F}_{1,336, p}\end{array}$ & $\begin{array}{l}\text { indocile } \\
(n=72)\end{array}$ & $\begin{array}{l}\text { ANOVA } \\
F_{1,91,} p\end{array}$ & $\begin{array}{c}\text { sibiricum } \\
\text { n. sp. }(n=21)\end{array}$ & $\begin{array}{c}\text { ANOVA } \\
\mathrm{F}_{1,285, p}\end{array}$ & $\begin{array}{c}\text { caespitum } \\
(n=266)\end{array}$ \\
\hline $\mathrm{CS}[\mu \mathrm{m}]$ & $781 \pm 48$ & $184.1,0.000$ & $692 \pm 53$ & $19.3,0.000$ & $754 \pm 71$ & $5.4,0.021$ & $781 \pm 48$ \\
\hline $\mathrm{CL} / \mathrm{CW}_{750}$ & $1.013 \pm 0.016$ & 0.05, n. s. & $1.013 \pm 0.016$ & 0.7, n.s. & $1.010 \pm 0.015$ & 1.0, n.s. & $1.013 \pm 0.016$ \\
\hline SLd/CS & $0.776 \pm 0.017$ & $9.0,0.000$ & $0.769 \pm 0.014$ & $109.3,0.000$ & $0.807 \pm 0.017$ & $62.9,0.000$ & $0.776 \pm 0.017$ \\
\hline $\mathrm{SWd} / \mathrm{CS}_{750}[\%]$ & $9.70 \pm 0.37$ & $25.8,0.000$ & $9.46 \pm 0.36$ & 2.5, n.s. & $9.59 \pm 0.26$ & 1.9, n.s. & $9.70 \pm 0.37$ \\
\hline PreOc/CS & $0.246 \pm 0.008$ & 1.2, n. s. & $0.247 \pm 0.008$ & $4.5,0.036$ & $0.243 \pm 0.007$ & 3.2, n.s. & $0.246 \pm 0.008$ \\
\hline PoOc/CL750 & $0.397 \pm 0.010$ & $20.9,0.000$ & $0.392 \pm 0.011$ & $7.2,0.009$ & $0.385 \pm 0.008$ & $34.1,0.000$ & $0.397 \pm 0.010$ \\
\hline $\mathrm{dCV}_{750}$ & $22.4 \pm 2.4$ & $5.7,0.018$ & $21.7 \pm 2.5$ & $15.6,0.000$ & $19.2 \pm 2.7$ & $35.9,0.000$ & $22.4 \pm 2.4$ \\
\hline $\mathrm{FL} / \mathrm{CS}_{750}$ & $0.392 \pm 0.011$ & $24.8,0.000$ & $0.385 \pm 0.011$ & $8.6,0.004$ & $0.378 \pm 0.009$ & $36.8,0.000$ & $0.392 \pm 0.011$ \\
\hline $\mathrm{EL} / \mathrm{CS}_{750}$ & $0.198 \pm 0.007$ & 0.4, n. s. & $0.197 \pm 0.007$ & $39.2,0.000$ & $0.208 \pm 0.007$ & $42.0,0.000$ & $0.198 \pm 0.007$ \\
\hline $\mathrm{EW} / \mathrm{CS}_{750}$ & $0.148 \pm 0.006$ & $13.6,0.000$ & $0.151 \pm 0.005$ & $7.0,0.010$ & $0.154 \pm 0.005$ & $20.4,0.000$ & $0.148 \pm 0.006$ \\
\hline $\mathrm{MW} / \mathrm{CS}_{750}$ & $0.650 \pm 0.012$ & $47.4,0.000$ & $0.638 \pm 0.012$ & $14.0,0.000$ & $0.650 \pm 0.013$ & 0, n.s. & $0.650 \pm 0.012$ \\
\hline $\mathrm{ML} / \mathrm{CS}_{750}$ & $1.182 \pm 0.022$ & 3.7, n. s. & $1.177 \pm 0.020$ & $42.0,0.000$ & $1.208 \pm 0.019$ & $28.2,0.000$ & $1.182 \pm 0.022$ \\
\hline SPBA/CS750 & $0.267 \pm 0.013$ & 0.4, n. s. & $0.266 \pm 0.011$ & $19.3,0.000$ & $0.254 \pm 0.009$ & $17.5,0.000$ & $0.267 \pm 0.013$ \\
\hline SPWI/CS 750 & $0.277 \pm 0.018$ & $21.0,0.000$ & $0.287 \pm 0.015$ & $33.3,0.000$ & $0.267 \pm 0.012$ & $7.0,0.009$ & $0.277 \pm 0.018$ \\
\hline PEW/CS 750 & $0.321 \pm 0.011$ & 1.8, n. s. & $0.323 \pm 0.013$ & $148.9,0.000$ & $0.286 \pm 0.010$ & $196.2,0.000$ & $0.321 \pm 0.011$ \\
\hline $\mathrm{PPW} / \mathrm{CS}_{750}$ & $0.413 \pm 0.013$ & 0.0, n. s. & $0.413 \pm 0.017$ & $44.2,0.000$ & $0.386 \pm 0.016$ & $88.6,0.000$ & $0.413 \pm 0.013$ \\
\hline PosSPI/CS & $0.418 \pm 0.015$ & $19.0,0.000$ & $0.427 \pm 0.016$ & 0.1, n.s. & $0.428 \pm 0.014$ & $8.7,0.003$ & $0.418 \pm 0.015$ \\
\hline PosSPu/CS750 & $0.086 \pm 0.020$ & $73.9,0.000$ & $0.063 \pm 0.017$ & 0.3, n.s. & $0.065 \pm 0.011$ & $20.4,0.000$ & $0.086 \pm 0.020$ \\
\hline$M P S P / C S_{750}$ & $0.440 \pm 0.015$ & $13.0,0.000$ & $0.447 \pm 0.016$ & 1.2, n.s. & $0.451 \pm 0.014$ & $11.7,0.001$ & $0.440 \pm 0.015$ \\
\hline $\mathrm{MPST} / \mathrm{CS}_{750}$ & $0.269 \pm 0.009$ & 1.0, n. s. & $0.270 \pm 0.008$ & $6.9,0.010$ & $0.265 \pm 0.008$ & $4.1,0.043$ & $0.269 \pm 0.009$ \\
\hline SPST/CS & $0.198 \pm 0.013$ & $21.7,0.000$ & $0.206 \pm 0.012$ & $9.8,0.002$ & $0.215 \pm 0.010$ & $33.4,0.000$ & $0.198 \pm 0.013$ \\
\hline $\mathrm{PLST} / \mathrm{CS}_{750}$ & $0.262 \pm 0.010$ & $4.9,0.028$ & $0.259 \pm 0.010$ & $23.5,0.000$ & $0.271 \pm 0.010$ & $17.0,0.000$ & $0.262 \pm 0.010$ \\
\hline MPPL/CS 750 & $0.359 \pm 0.010$ & $47.8,0.000$ & $0.350 \pm 0.012$ & 1.8, n.s. & $0.353 \pm 0.008$ & $6.9,0.009$ & $0.359 \pm 0.010$ \\
\hline PLSP/CS & $0.223 \pm 0.013$ & $5.4,0.020$ & $0.227 \pm 0.013$ & $25.3,0.000$ & $0.244 \pm 0.014$ & $47.3,0.000$ & $0.223 \pm 0.013$ \\
\hline $\mathrm{PEH} / \mathrm{CS}_{750}$ & $0.353 \pm 0.010$ & 3.0, n. s. & $0.351 \pm 0.011$ & $6.3,0.014$ & $0.344 \pm 0.009$ & $15.2,0.000$ & $0.353 \pm 0.010$ \\
\hline $\mathrm{PPH} / \mathrm{CS}_{750}$ & $0.360 \pm 0.010$ & 0.1, n. s. & $0.359 \pm 0.014$ & $30.0,0.000$ & $0.341 \pm 0.012$ & $63.0,0.000$ & $0.360 \pm 0.010$ \\
\hline PENL/CS & $0.258 \pm 0.010$ & $31.7,0.000$ & $0.251 \pm 0.011$ & $4.0,0.049$ & $0.255 \pm 0.009$ & 1.9, n.s. & $0.258 \pm 0.010$ \\
\hline MC1TG $_{750}$ & $10.5 \pm 2.7$ & $68.7,0.000$ & $13.6 \pm 2.9$ & $17.4,0.000$ & $16.6 \pm 3.2$ & $94.4,0.000$ & $10.5 \pm 2.7$ \\
\hline POTCOS750 & $8.4 \pm 1.8$ & $25.3,0.000$ & $7.2 \pm 2.2$ & $65.1,0.000$ & $11.4 \pm 1.8$ & $55.6,0.000$ & $8.4 \pm 1.8$ \\
\hline $\mathrm{PnHL} / \mathrm{CS}_{750}$ & $0.272 \pm 0.024$ & $95.1,0.000$ & $0.242 \pm 0.022$ & $56.4,0.000$ & $0.280 \pm 0.013$ & 2.2, n.s. & $0.272 \pm 0.024$ \\
\hline $\mathrm{ALPH}_{750}$ & $76.8 \pm 4.2$ & $37.6,0.000$ & $73.4 \pm 3.9$ & 1.8, n.s. & $72.1 \pm 3.2$ & $24.4,0.000$ & $76.8 \pm 4.2$ \\
\hline $\mathrm{BETA}_{750}$ & $46.5 \pm 2.2$ & $6.9,0.009$ & $47.4 \pm 3.0$ & $8.4,0.005$ & $49.5 \pm 2.7$ & $32.9,0.000$ & $46.5 \pm 2.2$ \\
\hline $\mathrm{GAMM}_{750}$ & $55.8 \pm 3.2$ & $8.4,0.004$ & $57.0 \pm 3.2$ & $5.8,0.018$ & $58.9 \pm 3.1$ & $18.7,0.000$ & $55.8 \pm 3.2$ \\
\hline $\mathrm{DELT}_{750}$ & $95.2 \pm 3.5$ & $85.9,0.000$ & $99.5 \pm 3.4$ & $15.5,0.000$ & $96.4 \pm 2.3$ & 2.2, n.s. & $95.2 \pm 3.5$ \\
\hline $\mathrm{EPSI}_{750}$ & $86.4 \pm 2.4$ & $37.6,0.000$ & $84.3 \pm 3.1$ & 0, n.s. & $84.3 \pm 2.8$ & $14.5,0.000$ & $86.4 \pm 2.4$ \\
\hline
\end{tabular}

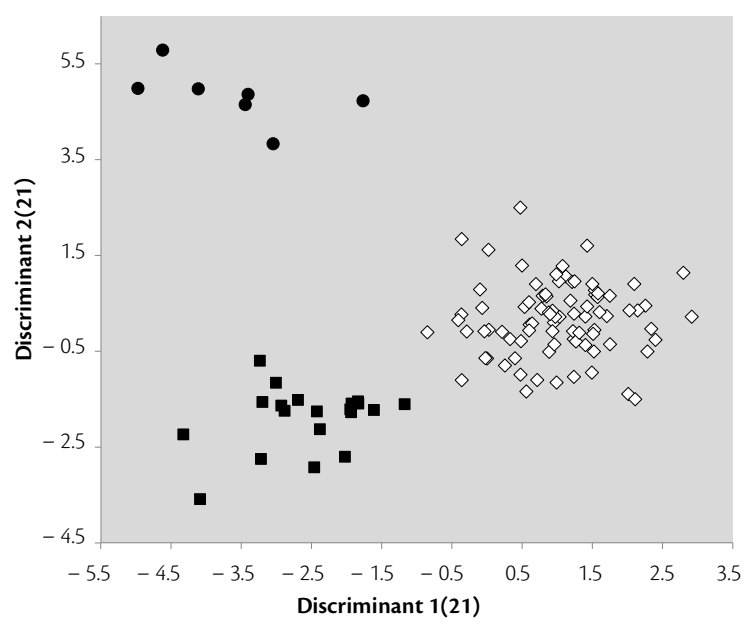

Figure 5. Nest sample means of individual values of a linear discriminant analysis of Tetramorium sibiricum n. sp. (black dots), $T$. indocile (black squares) and T. caespitum (white rhombs). Twenty-one phenotypic characters were considered which led to character overfitting in T. sibiricum n. sp. with only 21 worker individuals evaluated.

The methodology of species identification applied here is extremely complex and data recording is by far the most time-consuming of any ant genus investigated so far by the author - a challenge even for experienced and specialized investigators having access to adequate equipment. An

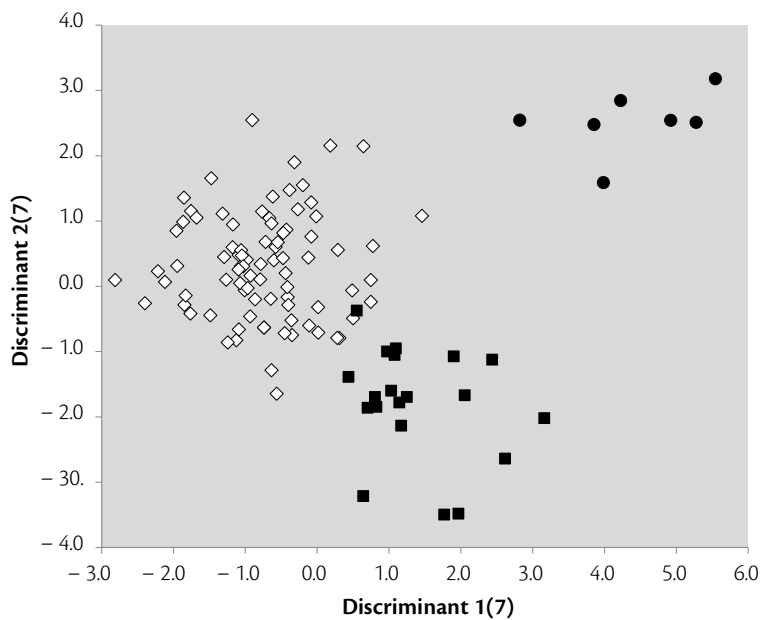

Figure 6. Nest sample means of a linear discriminant analysis of the first seven principal components extracted from twenty-one phenotypical characters in Tetramorium sibiricum n. sp. (black dots), $T$. indocile (black squares) and T. caespitum (white rhombs). The reduction to seven components avoids the danger of character overfitting in T. sibiricum n. sp. but weakened the discrimination of $T$. indocile and T. caespitum.

attempt to simplify the separation of the three West and Central Siberian species was done in writing a key that uses absolute primary data (i. e. without RAV-correction) and a strongly reduced character set. 
1. Postoculo-temporal area of head with rather many costae and costulae, POTCOS $11.4 \pm 2.1$. Anterior dorsum of $1^{\text {st }}$ gaster tergite with more complex elements of stickman-like or reticulate microsculpture, MC1TG $16.6 \pm 3.2$. Propodeal spines and eye slightly longer. With all linear measurements given in $\mathrm{mm}$, discriminant function $0.183^{*}$ POTCOS $+0.12^{*} \mathrm{MC} 1 \mathrm{TG}-34.79 * \mathrm{FL}$ $+46.67^{*} \mathrm{EL}+17.54^{*} \mathrm{ML}+28.28^{*} \mathrm{MPSP}-99.07^{*} \mathrm{PeW}-3.793>0$ [error $0 \%$ in 21 specimens]....

sibiricum n. sp.

- Postoculo-temporal area of head with fewer costae and costulae, POTCOS $8.4 \pm 2.4$. Anterior dorsum of $1^{\text {st }}$ gaster tergite with less complex elements of stickman-like or reticulate microsculpture, MC1TG $11.2 \pm 3.0$. Propodeal spines and eye slightly shorter. Discriminant $<0$ [error $0 \%$ in 338 specimens].
2. Longest hair near anterolateral pronotal corner shorter, $\mathrm{PnHL}$ $0.168 \pm 0.020 \mathrm{~mm}$. Anterior dorsum of $1^{\text {st }}$ gaster tergite with more complex elements of stickman-like microsculpture, MC1TG $13.5 \pm 2.8$. With all linear measurements given in $\mathrm{mm}$, discriminant $0.127^{*}$ POTCos $-0.173^{*} \mathrm{MC} 1 \mathrm{TC}+85.54^{*} \mathrm{SWd}-$ 49.08* MPSP $+62.52 * \mathrm{MPPL}+21.985^{*} \mathrm{PnHL}-9.026<0$ [error $9.7 \%$ in 72 specimens] ............................................indocile

- Longest hair near anterolateral pronotal corner longer, $\mathrm{PnHL} 0.212 \pm 0.022 \mathrm{~mm}$. Anterior dorsum of $1^{\text {st }}$ gaster tergite with only scattered and less complex elements of stickman-like microsculpture, MC1TG $10.6 \pm 2.7$. Discriminant > 0 [error $1.9 \%$ in 266 specimens]

\section{TETRAMORIUM SIBIRICUM N. SP.}

ZooBank http://zoobank.org/9D40E9DB-FD06-444B-86DC-300297D049D5

\section{Etymology}

The name of the species refers to the region where the species is occurring.

\section{Type material}

Depository of all specimens: SMN Görlitz (Germany).

- Holotype plus four paratype workers labelled "RUS: 51.04806 N, 106.16686 E, Gusinoye Ozero - 10 SW, 615 m, stony steppe, under stone, I. ANTONOV 2013.07.04-153 S".

- five paratype workers labelled "RUS: $51.04742 \mathrm{~N}$, 106.16703 E, Gusinoye Ozero - 10 SW, 601 m, stony steppe, under stone, I. ANTONOV 2013.07.04 - 154_S".

- four paratype workers labelled "RUS: $51.04786 \mathrm{~N}$, 106.16694 E, Gusinoye Ozero - 10 SW, 609 m, stony steppe, under stone, I. ANTONOV 2013.07.04-155 S".

- four paratype workers labelled "RUS: $51.04778 \mathrm{~N}$, 106.16689 E, Gusinoye Ozero - 10 SW, 608 m, stony steppe, under stone, I. ANTONOv 2013.07.06-156_S".

- four paratype workers labelled "RUS: $51.04772 \mathrm{~N}$, 106.16689 E, Gusinoye Ozero - 10 SW, 600 m, stony steppe, under stone, I. Antonov 2013.07.06 - 157".

- four paratype workers labelled "RUS: $51.04800 \mathrm{~N}$ 106.16697 E, Gusinoye Ozero - 10 SW, 615m, stony steppe, under stone, I.Antonov 2013.07.06-176_S".

- four paratype workers labelled "RUS: $50.43683 \mathrm{~N}$ 106.12525 E, Naushki village $-5 \mathrm{~km} \mathrm{~N}, 851 \mathrm{~m}$, in soil, dirt road, forest-steppe, I. ANTONOv 2013.07.10 - 145_s".

\section{Geographic range}

Only known so far from the two type localities. Apparently, a species restricted to Siberia.

\section{Description}

Worker (table I, figures 7-9). Medium-sized, mean $\mathrm{CS}=754 \mu \mathrm{m}$. Scape longest within the T. caespitum complex (TCC), mean SL / CS 750 0.807. Eye rather long, mean $\mathrm{EL} / \mathrm{CS}_{750}$ 0.208. Pronotal setae very long, mean $\mathrm{PnHL} / \mathrm{CS}_{750} 0.280$. Mesosoma long and wide, mean $\mathrm{ML} / \mathrm{CS}_{750} 1.208$, mean $\mathrm{MW} / \mathrm{CS}_{750}$ 0.650. Petiole narrowest within the TCC, mean

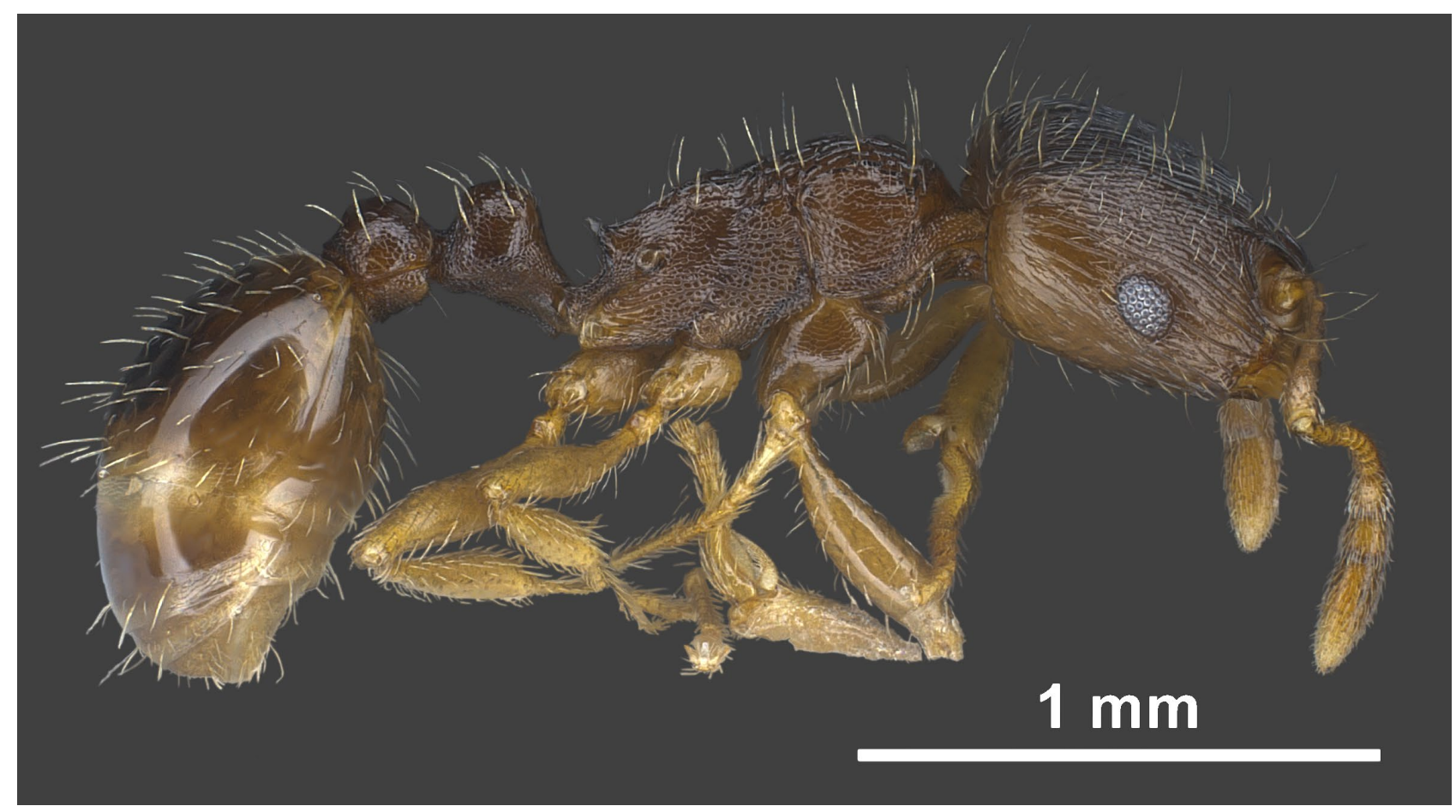

Figure 7. Lateral aspect of the holotype worker of Tetramorium sibiricum n. sp. Photo R. SCHULTZ. 


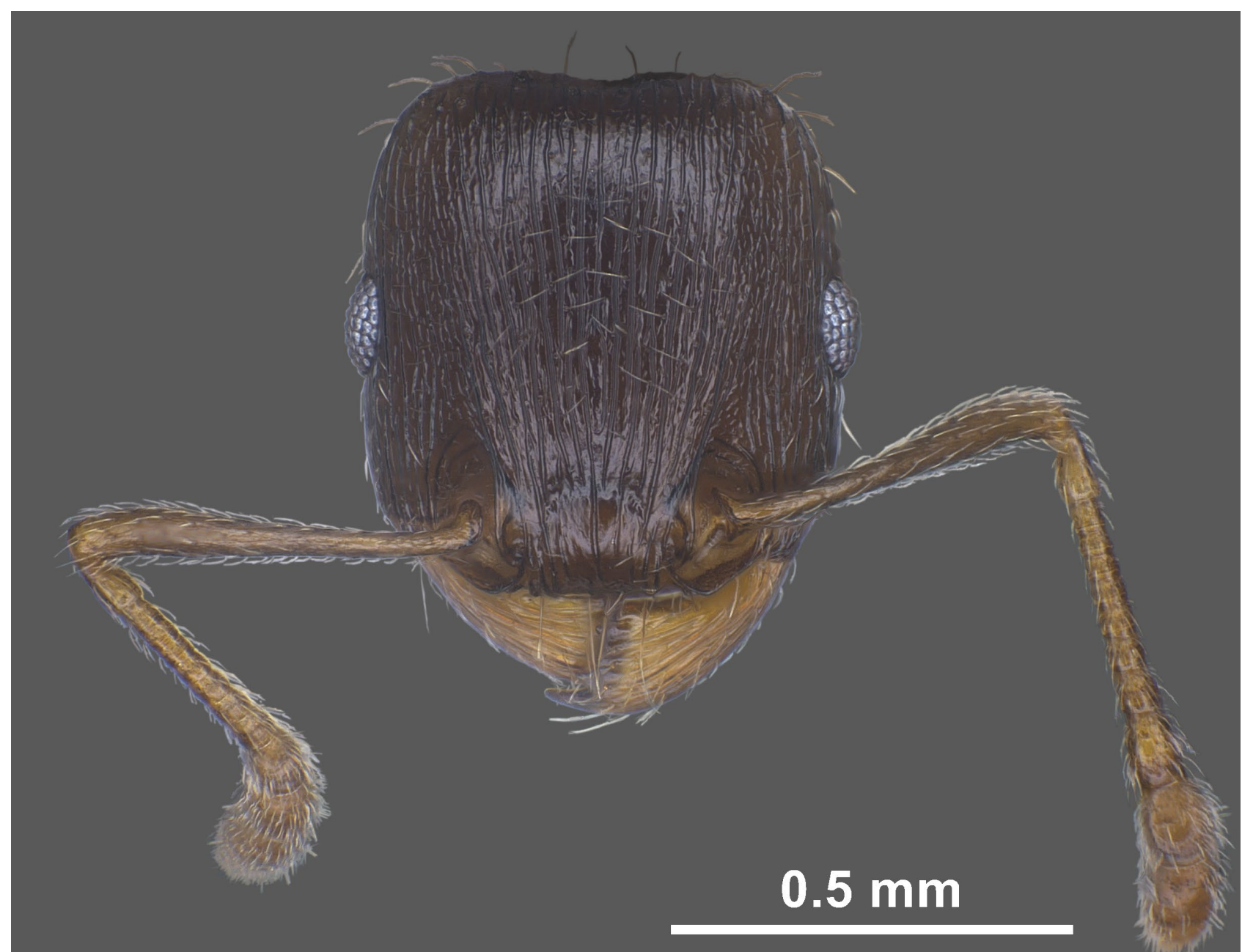

Figure 8. Dorsal aspect of the head of the holotype worker of Tetramorium sibiricum n. sp. Photo R. SCHULTz.

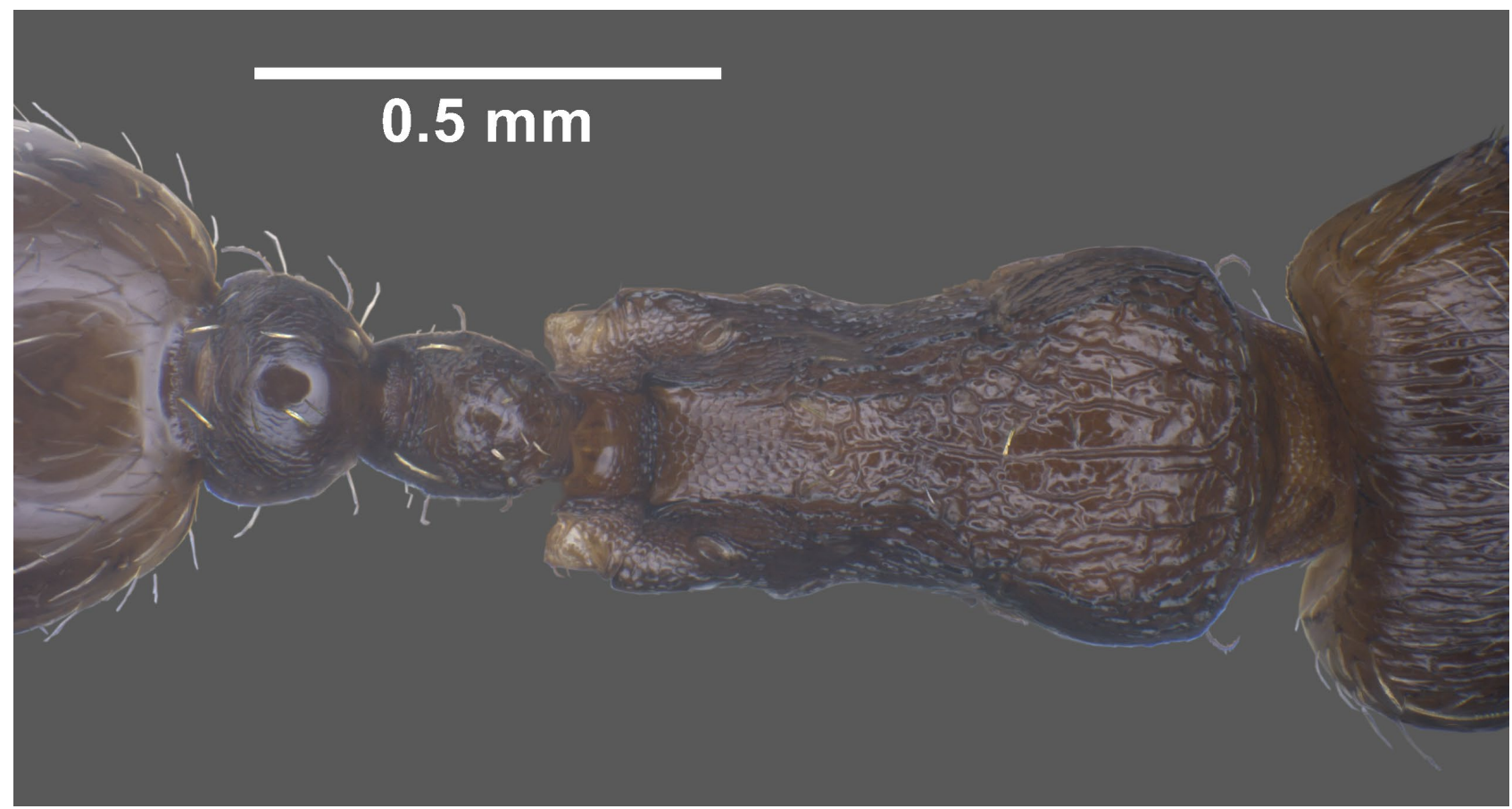

Figure 9. Dorsal aspect of mesosoma and waist segments of the holotype worker of Tetramorium sibiricum n. sp. Photo R. SCHULTZ.

PeW / $\mathrm{CS}_{750}$ 0.286. Spines longest within the TCC, mean SPST / $\mathrm{CS}_{750}$ 0.215. Postpetiole height low, $\mathrm{PpH} / \mathrm{CS}_{750} 0.340$. Head dorsum and occiput with rather coarse longitudinal costae and costulae, the interstices with delicate microreticulate structures. Mesosoma dorsum coarsely longitudinally rugulose, the interstices delicately microreticulate. Central dorsum of petiole and postpetiole nodes smooth and shiny but very finely microreticulate or with stickman-like elements of microsculpture. Dorsum of $1^{\text {st }}$ gaster tergite brilliantly shiny but the scattered elements 
of microsculpture are more complex than in the average of the TCC, mean MC1TG 750 16.6. Postoculo-temporal area of head with rather many costae and costulae, mean POTCOS $_{750}$ 11.4. Color of whole body homogenously dark to light brown. The gyne and the male are unknown.

\section{Consideration of synonymies}

T. sibiricum n. sp. shows a rather unique character combination making its identification comparatively easy. It has been stated above that taxa described from east and southeast of the Reinig Line - from China, Korea and Japan in particular - are very unlikely to have invaded the extremely winter-cold Central Siberia. Apart from climatic reasons, there are also morphological arguments to exclude synonymies. The images of a type of Tetramorium jacoti WHEELER, 1927 (specimen CASENT0901253 in www.antweb.org), described from Tartar City / Peking and of a type of T. tsushimae EMERY, 1925 (CASENT0904809 in www.antweb.org), described from Tsushima /Japan probably refer to the same species. This assumption is based on similarities in sculpture and mesosomal shape and zoogeographic proximity. These types differ from the T. sibiricum n. sp. condition in having shorter mesosomal setae and the spine tips reaching more dorsad relative to the level of the dorsal mesosomal profile. Tetramorium annectens PISARSKI,1969 from Pei-Hai / Peking was described by WHEELER (1927) to have the petiole and postpetiole "subopaque and sculptured throughout, the former irregularly rugulose, the latter regularly longitudinally rugulose". This strongly contrasts the situation in T. sibiricum n. sp. and is confirmed by the image of a $T$. annectens type (CASENT0916601 in www.antweb.org). The image additionally shows a remarkably strong longitudinal sculpture at the base of the first gaster tergite - a character not observed in any species of the TCC. Notably, these two characters strongly contradict BOLTON's proposal (BOLTON, 1995) of T. annectens being a junior synonym of T. tsushimae.
Four taxa described on species level from China by WANG et al. (1988) are fully excluded as synonyms of T. sibiricum n. sp. due to most deviating morphology and climate niches.

It was stated above that there is no taxon other than $T$. caespitum and T. indocile from west and southwest of the Reinig line approaching T. sibiricum n. sp. in the combination of phenotype and climate niche. Yet, Tetramorium caespitum var. barabensis RUZSKY, 1925, described from Karachinskoe Ozero (probably $55.35^{\circ} \mathrm{N}, 76.96^{\circ} \mathrm{E}$ ) near Tomsk / West Siberia requires consideration. The original description gives the following data: "Head weakly shiny; dorsum of promesonotum very smooth ('so znachitel'no sglazhennoi skul'pturoj'); sides of both waist segments fully smooth, furthermore postpetiole narrowed, having the width of petiole, from above flatter ('sverkhu bolee ploskij'). Color light, head brownish-cinnamon, mesosoma brownishyellowish; mandibles, scapes and tarsae yellow. Size 2.1-3 $\mathrm{mm}$. Nesting in soil under a stone in rout sprouts of Stipa pennata, sunny tschernozem northeast of the health resort." This description makes a synonymy with $T$. sibiricum $n$. sp. unlikely. The weak sculpture of T. barabense rather points to $T$. caespitum or $T$. indocile as well as the mean ratio $\mathrm{PpW} / \mathrm{PeW}$ which is 1.349 in T. sibiricum n. sp. but 1.286 in $T$. caespitum and 1.284 in T. indocile. According to RADCHENKO (1992), types of T. barabense are unknown but, if they should be discovered, the taxon could turn out as senior synonym of $T$. indocile. The former taxon is considered here as incertae sedis as long as no conclusive species identification is possible.

\section{Biology}

All seven nests were collected under stones. The sparse information currently available suggests that Tetramorium sibiricum n. sp. is distributed in more natural steppe habitats whereas sympatric T. caespitum seems to occur in habitats with anthropogenous influence.

\section{ACKNOWLEDGMENTS}

I wish to thank Igor ANTONOv (Irkutsk, Russia) for donating a lot of interesting ant samples from Central Siberia throughout the last years, Roland SCHULTZ (Görlitz, Germany) for producing fine z-stack images of the holotype, Herbert WAGNeR (Graz, Austria) and Mike Fox
(London, United Kingdom) for reviewing, Benoît GESLIN (Marseille, France) for editing and reviewing as well as Mehdi ISSERTES (Aurillac, France) and Tanguy JEAN (Lille, France) for the layout. 


\section{REFERENCES}

BOLTON, B. (1995). A new general catalogue of the ants of the world. Harvard University Press, Cambridge \& London, 504 pp.

CsÖsZ, S. \& B. L. FISHER (2015). Diagnostic survey of Malagasy Nesomyrmex species-groups and revision of hafahafa group species via morphology based cluster delimitation protocol. ZooKeys, 526: 19-59. https://doi.org/10.3897/zookeys.526.6037

De LatTin, G. (1967). Grundriss der Zoogeographie. Fischer, Jena (Germany), 602 pp.

DLUSSKY, G. M. (1967). Murav'i roda Formica. Izdatel'stvo "Nauka", Moscow, $216 \mathrm{pp}$

Francoeur, A. (1983). The ant fauna near the tree-line in Northern Quebec (Formicidae, Hymenoptera). Nordicana, 47: 177-180. https://www.antwiki.org/wiki/images/1/14/Francoeur_1983.pdf [accessed 15 February 2021]

RAdCHENKO, A. G. (1992). Murav'i roda Tetramorium (Hymenoptera, Formicidae) fauny SSSR. Soobshchenie 2. Zoologichesky Zhurnal, 71(8): 50-58

https://antcat.org/references/127950

[accessed 15 February 2021]

RUZSKY, M. (1925). Material po faune kurorta "Karachinskoe Ozero". Izvestiya Tomskogo Gosudarstvennogo Universiteta, 75: 283-290. https://antcat.org/references/128193 [accessed 15 February 2021]

SEIFERT, B. (2000). A taxonomic revision of the ant subgenus Coptoformica MUelLer, 1923. Zoosystema, 22(3): 517-568. https://sciencepress.mnhn.fr/fr/periodiques/zoosystema/22/3/re vision-taxonomique-des-fourmis-du-sous-genre-coptoformicamueller-1923-hymenoptera-formicidae [accessed 15 February 2021]

SEIFERT, B. (2008). Removal of allometric variance improves species separation in multi-character discriminant functions when species are strongly allometric and exposes diagnostic characters. Myrmecological News, 11: 91-105.

https://myrmecologicalnews.org/cms/index.php?option=com_c ontent\&view $=$ category\&id $=247 \& \mid$ temid $=355$

[accessed 15 February 2021]
SEIFERT, B. (2018). The Ants of Central and North Europe. Lutra Verlagsund Vertriebsgesellschaft, Tauer (Germany), 408 pp.

SeIFERT, B. (2020). Revision of the Plagiolepis schmitzii group with description of Pl. invadens sp. nov. - a new invasive supercolonial species (Hymenoptera: Formicidae). Deutsche Entomologische Zeitschrift, 67(2): 183-196. https://doi.org/10.3897/dez.67.53199

SEIFERT, B. (2021). A taxonomic revision of the Palaearctic members of the Formica rufa group (Hymenoptera, Formicidae) - the famous mound-building red wood ants. Myrmecological News, 31: 133179. https://doi.org/10.25849/myrmecol.news_031:133

SEIIERT, B., M. RITZ \& S. CSÖSZ (2013). Application of Exploratory Data Analyses opens a new perspective in morphology-based alphataxonomy of eusocial organisms. Myrmecological News, 19: 1-15. https://myrmecologicalnews.org/cms/index.php?option=com_c ontent\&view $=$ category\&id $=574 \& \mathrm{ltemid}=363$ [accessed 15 February 2021]

Steiner, F.M., B. Seifert, K. Moder \& B. SChlick-Steiner (2010). A multisource solution for a complex problem in biodiversity research: Description of the cryptic ant species Tetramorium alpestre sp.n. (Hymenoptera: Formicidae). Zoologischer Anzeiger, 249(3-4): 223-254. https://doi.org/10.1016/j.jcz.2010.09.003

Wagner, H., W. Arthofer, B. Seifert, C. Muster, F. M. Steiner \& B. C. SCHLICK-STEINER (2017). Light at the end of the tunnel: Integrative taxonomy delimits cryptic species in the Tetramorium caespitum complex (Hymenoptera, Formicidae). Myrmecological News, 25: 95-129. https://doi.org/10.25849/myrmecol.news_025:095

WANG, M., XIAO, G. \& J. WU (1988). Taxonomic studies on the genus Tetramorium Mayr in China (Hymenoptera, Formicidae). [In Chinese]. Forest Research, 1: 264-274. https://doi.org/10.5281/zenodo.24951

WHEELER, W.M. (1927). Chinese ants collected by Professor S. F. LIGHT and Professor N. Gist GeE. American Museum Novitates, 255: 1 12. http://hdl.handle.net/2246/4193

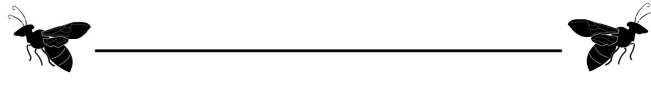

OSMIA est éditée par l'Observatoire des Abeilles (OA), une association loi 1901 d'apidologues (ou mellitologues) d'Europe francophone qui œuvrent pour la connaissance et la protection des Abeilles sauvages

Les articles sont:

- publiés uniquement en ligne

- disponibles en open access

- indexés / archivés par Crossref, Zoobank, HAL, Zenodo, OpenAIRE, Google Scholar et Web of Science (Clarivate) OpenAlRE, Google Schical
[Zoological Record].

- [Zoological Record], respectueux des recommandations de la Com
internationale de Nomenclature zoologique (ICZN),

- sous Licence Creative Commons Attribution International CC BY 4.0 qui autorise la reproduction et la diffusion du document, à condition d'en citer explicitement la source.

- librement déposables sur des sites internet ou des plateformes d'archivage.

(!) Les documents d'autres sources et non distribuées sou licence libre sont reproduits après autorisation (à demander par les auteurs) et demeurent la propriété des auteurs ou éditeurs originaux

(!) Le contenu publié est sous l'entière responsabilité des (!) Le cont

OSMIA est conçue pour une impression recto-verso en haute résolution. Les bibliothèques publiques, les laboratoires, les muséums et les associations sont invités à imprimer et conserver une version papier de la revue.
OSMIA is published by the Observatory of Bees (OA), a nonprofit society of apidologists (or mellitologists) from Frenchspeaking Europe who work together for the knowledge and protection of wild bees

The items are:

- published only online

- available in open access

- indexed / archived by Crossref, Zoobank, HAL, Zenodo OpenAIRE, Google Scholar and Web of Science (Clarivate) [Zoological Record]

- respectful of the recommendations of the International - respectful of the recommendations of the Int
Commission for Zoological Nomenclature (ICZN),

- under Creative Commons Attribution Licence International under Creative Commons Attribution Licence International
CC BY 4.0 which authorises the reproduction and distribution of the document, provided the source is explicitly cited

- freely depositable on personal or institutional websites and archiving platforms.

(!) Documents from other sources and not distributed under a free license are reproduced after authorisation (to be requested by the authors) and remain the property of the original authors or publishers.

(!) The published content is the sole responsibility of the
a authors.

OSMIA is designed for high-resolution printing on both sides. Public libraries, laboratories, museums, and societies are invited to print and keep a paper version of the journal.

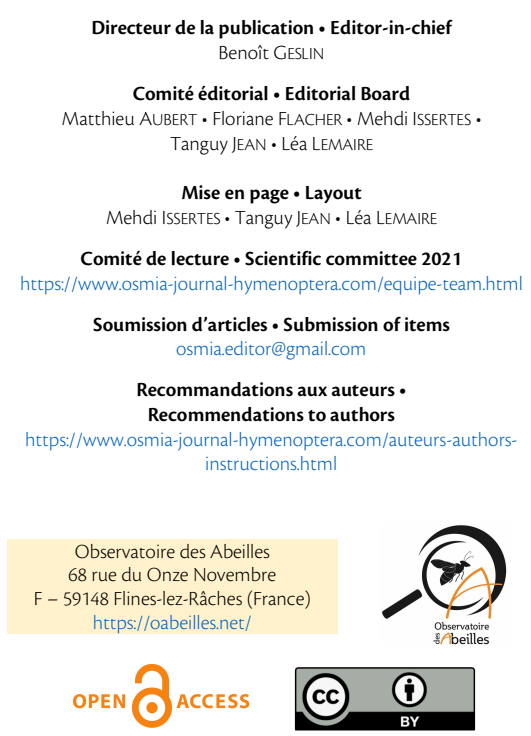

